\title{
PARAMETER UNCERTAINTY AND SENSITIVITY IN A LIQUID-EFFLUENT DOSE MODEL
}

\author{
T. C. HYMAN \\ Department of Nuclear Engineering Sciences, University of Florida, Gainesville, FL 32611, U.S.A. \\ and \\ D. M. HAMBY* \\ Department of Environmental and Industrial Health, University of Michigan, Ann Arbor, MI \\ 48109-2029, U.S.A.
}

(Received: January 1995; revised: April 1995)

\begin{abstract}
Radioactive materials which are released into streams on the Savannah River Site (SRS) eventually flow into the Savannah River. Tritium, ${ }^{90} \mathrm{Sr},{ }^{137} \mathrm{Cs}$, and ${ }^{239} \mathrm{Pu}$ account for the majority of the radiation dose received by users of the Savannah River. This paper focuses on the dose uncertainties originating from variability in parameters describing the transport and uptake of these nuclides. Parameter sensitivity has also been determined for each liquid pathway exposure model. The models used here to estimate radiation dose to an exposed individual provide a range of possible dose estimates that span approximately one order of magnitude. A pathway analysis reveals that aquatic food and water consumption account for more than $95 \%$ of the total dose to an individual.
\end{abstract}

\section{Introduction}

Radioactive materials which are released into streams on the Savannah River Site (SRS) eventually flow into the Savannah River. These radionuclides are transported down the river with the potential to expose Savannah River users to radiation. Exposure pathways include ingestion of contaminated water and aquatic food (fish or invertebrates) and external exposure from swimming, boating, and shoreline usage. Irrigation of crops presents an additional exposure pathway; however, there is no known usage of the Savannah River for large-scale irrigation (Hamby, 1992a).

Historically, four radionuclides have accounted for over $99 \%$ of the radiation dose received by users of the Savannah River from exposure to chronic aqueous releases of radioactive materials (WSRC, 1989; WSRC, 1990; WSRC, 1991). Since these four radionuclides dominate the liquid effluent dose, the uncertainty analysis performed in this work will focus on the uncertainties associated with parameter values describing their environmental transport and uptake. The 1992 operating year has been chosen for this analysis since it is representative of annual aqueous releases expected from future operations at the SRS.

Ideally, the dosimetric impact to Savannah River users would be estimated using measured radionuclide concentrations. However, only tritium and trace amounts of Sr-90 and Cs-137 are detected in the river water. For released materials that

* To whom correspondence should be addressed. 
have river concentrations too low to detect, the radiation dose is calculated using mathematical models similar to the models developed by the United States Nuclear Regulatory Commission (USNRC, 1977). Estimation of the offsite dose is essential to ensuring compliance with appropriate exposure guidelines and dose limits set by the Department of Energy and the Environmental Protection Agency.

This work will quantify the uncertainty associated with the dose estimates calculated for radionuclides that dominate the offsite liquid pathway dose. The dose equivalent will be estimated using models for determining radiation dose resulting from chronic exposure to liquid radioactive effluents. Based on current literature, inodel parameters will be assigned a range and distribution of possible values. Then, using Latin hypercube techniques, dose calculations will be performed to provide a distribution of dose estimates. Using this information, conclusions may be drawn as to the uncertainty of the deterministic dose estimates resulting from parameter variability and uncertainty.

In addition to providing information on the uncertainty of model predictions, analysis of the results will allow for the determination of model sensitivity to each input parameter. Identification of the most sensitive model parameters provides information on the relative importance of that parameter to the estimation of radiation dose.

\section{Materials and Methods}

\subsection{MODEL FOR THE AQUEOUS PATHWAY DOSE ESTIMATES}

Mathematical models are used to calculate the radiation dose to a hypothetical individual from chronic liquid releases. Radionuclide concentrations in the Savannah River are estimated by a transport model which assumes a continuous and constant release over a one-year period. Dose estimates are generated for an individual assumed to reside on the shore of the Savannah River at a location downstream where complete mixing occurs, and to consume contaminated fish and untreated river water. This individual is also assumed to be engaged in shoreline recreational activities as well as swimming and boating on the Savannah River during the course of the release year.

The pathway models utilized in this study are presented in Table I. The models are based on those published in the USNRC's Regulatory Guide 1.109 (1977) and introduced in publications by Oak Ridge National Laboratory (Simpson and McGill, 1977). Parameter definitions are given in Table II. 


\section{TABLE I}

Transport and dosimetry models for estimating radiation dose from aqueous releases

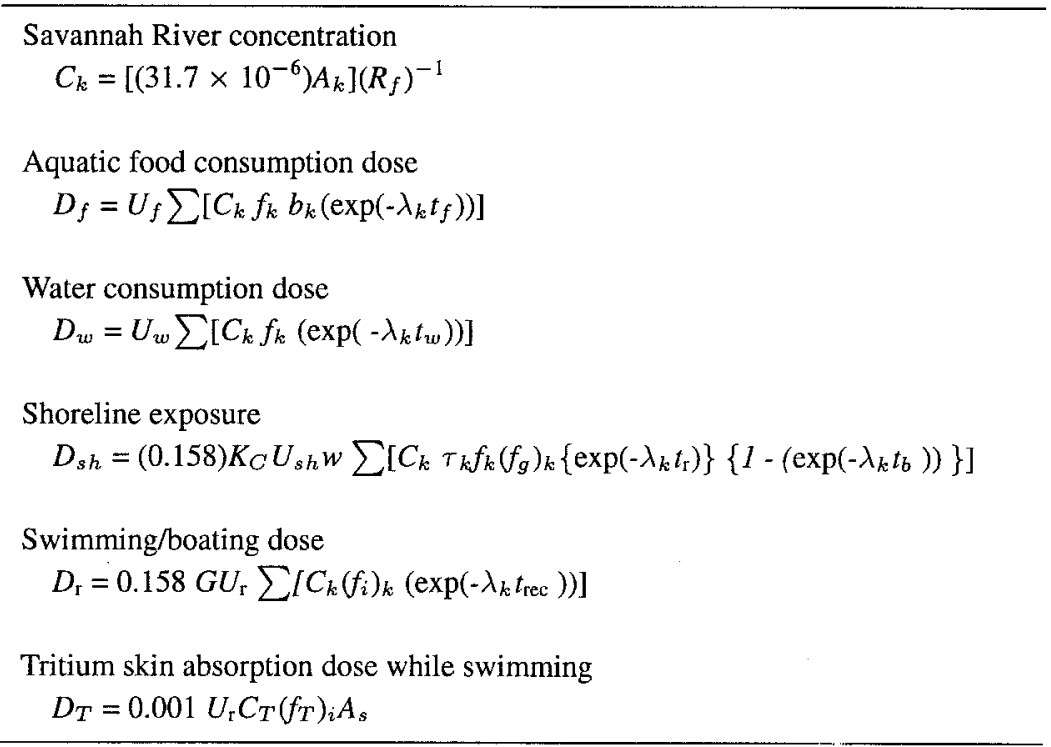

\subsection{DEVELOPMENT OF THE INPUT PARAMETER DISTRIBUTIONS}

Each parameter used in the dose models is defined by a probability distribution which best represents its range of possible values. A summary of the following information is presented in Table III.

Savannah river flow rate, $R_{f}$. The flow rate of the Savannah River is used to determine the concentration of radionuclides in river water. The prominent location for measuring the flow rate downstream from the Savannah River Site is at Burton's Ferry Bridge (Highway 301), approximately $37 \mathrm{~km}$ downstream. Multiple daily measurements taken by the United States Geological Survey (USGS) at Highway 301 are averaged to give a daily flow rate for tabulation in Water Resource Data Reports (USGS, 1993). These reports served as the source of data for determining the annual average flow rate of the Savannah River for 1992.

A normal distribution was assigned to the river flow rate parameter since an annual average value was determined from daily average flow rates (Tsoulfanidis, 1983). River flow data for 1992 result in a mean of $340 \mathrm{~m}^{3} \mathrm{~s}^{-1}$. The standard deviation, determined from the variation of the mean annual flow rate was $1.1 \mathrm{~m}^{3} \mathrm{~s}^{-1}$.

Shoreline and recreational usage factors, $U_{s h}$ and $U_{\mathrm{r}}$. Shoreline and recreational (swimming and boating) usage of the Savannah River was estimated using data 
TABLE II

Definition of input parameters for the aquatic pathway models in Table I

\begin{tabular}{ll}
\hline Parameter & Definition \\
\hline River concentration \\
$C_{k}$ & River concentration of nuclide $k, \mathrm{~Bq}^{-1}$ \\
$A_{k}$ & Activity of nuclide $k$ released annually, $\mathrm{MBq}^{-1}$ \\
$R_{f}$ & Average annual Savannah river flow rate, $\mathrm{m}^{3} \mathrm{~s}^{-1}$ \\
$31.7 \times 10^{-6}$ & Conversion factor, $\mathrm{y} \mathrm{m}^{3} \mathrm{~Bq}^{-1} \mathrm{~s}^{-1} \mathrm{MBq}^{-1}$ \\
Aquatic food ingestion \\
$D_{f}$ & 50-year committed dose from consumption of aquatic foods, uSv \\
$U_{f}$ & Aquatic food consumption rate, $\mathrm{kg} \mathrm{y}^{-1}$ \\
$f_{k}$ & Ingestion dose factor for nuclide $k, \mu \mathrm{Sv} \mathrm{Bq}^{-1}$ \\
$b_{k}$ & Bioaccumulation factor for nuclide $k, 1 \mathrm{~kg}^{-1}$ \\
$\lambda_{k}$ & Radiological decay constant for nuclide $k, \mathrm{~d}^{-1}$ \\
$t_{f}$ & Transport time from harvest to consumption, $\mathrm{d}$ \\
Water ingestion & \\
$D_{w}$ & 50-year committed dose from water ingestion, $\mu \mathrm{Sv}$ \\
$W_{w}$ & Water consumption rate, $1 \mathrm{y}-1$ \\
$f_{k}$ & Ingestion dose factor for nuclide $k, \mu \mathrm{Sv} \mathrm{Bq}^{-1}$ \\
$t_{w}$ & Transport time from release point to location downstream where consumption \\
\end{tabular}

Shoreline activities

\begin{tabular}{|c|c|}
\hline$D_{\text {sh }}$ & Annual external dose from shoreline activities, $\mu \mathrm{Sv}$ \\
\hline$K_{c}$ & Water-to-sediment transfer constant, $1 \mathrm{~kg}^{-1} \mathrm{~h}^{-1}$ \\
\hline$U_{\text {sh }}$ & Shoreline usage factor; shoreline sediments exposure time, $h$ \\
\hline$w$ & Shoreline width factor \\
\hline$\tau_{k}$ & Radiological half-life of nuclide $k, \mathrm{~d}$ \\
\hline$\left(f_{g}\right)_{k}$ & Ground-shine dose factor for nuclide $k, \mathrm{~m}^{2} \mu \mathrm{Sv} \mathrm{Bq}^{-1} \mathrm{y}^{-1}$ \\
\hline$t_{\mathrm{r}}$ & Time from release to exposure, $\mathrm{d}$ \\
\hline$t_{b}$ & Time sediment is exposed to contaminated water, $y$ \\
\hline 0.158 & Conversion factor, $\mathrm{y} \mathrm{kg} \mathrm{m} \mathrm{m}^{-2} \mathrm{~d}^{-1}$ \\
\hline
\end{tabular}

Recreational activities

$D_{\mathrm{r}} \quad$ Annual dose received from swimming and boating, $\mu \mathrm{Sv}$

$U_{\mathrm{r}} \quad$ Recreation usage factor; time spent swimming and boating annually, $\mathrm{h}$

$G \quad$ Geometry factor for swimming and boating

$\left(f_{i}\right)_{k} \quad$ Water immersion dose factor for nuclide $k, \mathrm{~m}^{3} \mu \mathrm{Sv} \mathrm{Bq} \mathrm{B}^{-1} \mathrm{y}^{-1}$

$\left(t_{\text {rec }} \quad\right.$ Time from release to exposure while recreating, $\mathrm{h}$

0.114 Conversion factor, $1 \mathrm{y} \mathrm{m}^{-3} \mathrm{~h}^{-1}$

Tritium absorption

$D_{T} \quad 50$-year committed dose from absorption of tritium, $\mu \mathrm{Sv}$

$U_{\text {sw }} \quad$ Annual swimming usage, $\mathrm{h}$

$C_{T} \quad$ Tritium concentration in the Savannah River, $\mathrm{Bq} \mathrm{I}^{-1}$

$\left(f_{T}\right)_{i} \quad$ Ingestion dose factor for tritium, $\mu \mathrm{Sv} \mathrm{Bq}^{-1}$

$A_{s} \quad$ Skin absorption rate for tritium, $\mathrm{ml} \mathrm{h}^{-1}$

0.001 Conversion factor, $1 \mathrm{ml}^{-1}$ 
TABLE III

Parameter distributions and characteristics ${ }^{\mathrm{a}}$

\begin{tabular}{llll}
\hline Parameter & $\begin{array}{l}\text { Distribution } \\
\text { type }\end{array}$ & Units & Characteristics \\
\hline$R_{f}$ & $\mathrm{~N}$ & $\mathrm{~m}^{3} \mathrm{~s}^{-1}$ & $340,1.1$ \\
$K_{c}$ & $\mathrm{U}$ & $1 \mathrm{~kg}^{-1} \mathrm{~h}^{-1}$ & $0.00172,0.72$ \\
$w$ & $\mathrm{~T}$ & Dimensionless & $0.1,0.2,1$ \\
$A_{s}$ & $\mathrm{~N}$ & $\mathrm{ml} \mathrm{h}^{-1}$ & 35,8 \\
Usage factor & & & \\
$U_{f}$ & $\mathrm{LN}$ & $\mathrm{kg} \mathrm{y}^{-1}$ & $7.7,2.1$ \\
$U_{w}$ & $\mathrm{LN}$ & $1 \mathrm{y}^{-1}$ & $410,1.6$ \\
$U_{s h}$ & $\mathrm{~T}$ & $\mathrm{~h}$ & $12,23,39$ \\
$U_{\mathrm{r}}$ (swimming) & $\mathrm{T}$ & $\mathrm{h}$ & $4.5,8.9,15$ \\
$G$ (swimming) & constant & - & 1.0 \\
$U_{\mathrm{r}}$ (boating) & $\mathrm{T}$ & $\mathrm{h}$ & $13,25,43$ \\
$G$ (boating) & constant & - & 0.5 \\
Bioconcentration factor for & & \\
freshwater organisms, $b_{k}$ & & $0.9,1.0,1.0$ \\
Tritium & $\mathrm{T}$ & $1 \mathrm{~kg}^{-1}$ & $0.3,300$ \\
Strontium & $\mathrm{U}$ & $1 \mathrm{~kg}^{-1}$ & $30,1.5 \times 10^{4}$ \\
Cesium & $\mathrm{U}$ & $1 \mathrm{~kg}^{-1}$ & $0.35,35$ \\
Plutonium & $\mathrm{U}$ & $1 \mathrm{~kg}^{-1}$ & $390,510,660$ \\
Release amount, & $A_{k}$ & & $15,29,58$ \\
Tritium & $\mathrm{T}$ & $\mathrm{Bq}$ & $2.9,3.7,4.8$ \\
Strontium & $\mathrm{T}$ & $\mathrm{kBq}$ & $0.30,0.60,1.2$ \\
Cesium & $\mathrm{T}$ & $\mathrm{kBq}$ & \\
Plutonium & $\mathrm{T}$ & $\mathrm{kBq}^{-1}$ & \\
\hline
\end{tabular}

${ }^{a}$ Distribution type and characteristics: $\mathrm{N}$, normal - (mean; standard deviation); LN, lognormal - (geometric mean, geometric standard deviation); $\mathrm{U}$, uniform - (minimum value; maximum value); $\mathrm{T}$, triangular - (minimum value; mode; maximum value).

provided by the Georgia Department of Natural resources (GDNR, 1990). Data gathered by the GDNR include estimates of the participating population, the average frequency of the recreational activity per participating individual, and the average number of hours per occasion (GDNR, 1990).

Shoreline, boating and swimming statistics for the hypothetical individual at the SRS have been determined previously (Hamby, 1992a). Shoreline usage was estimated using the available data for warmwater fishing (GDNR, 1990). Individual shoreline usage was calculated to average $23 \mathrm{~h} \mathrm{y}^{-1}$. Boating usage was calculated using data from the boating/sailing, canoeing/rafting, and waterskiing entries in the report by the GDNR (1990) and was determined to average $25 \mathrm{~h} \mathrm{y}^{-1}$ for the 
Savannah River Site. Approximately $8.9 \mathrm{~h} \mathrm{y}^{-1}$ are spent by the average individual swimming in the Savannah River.

Triangular distributions were assigned to the individual usage factors due to a lack of data necessary to determine a distribution profile. Endpoints were arbitrarily chosen by varying each value used in the calculation of the individual usage by \pm $20 \%$ and recalculating usage to determine maximum and minimum values.

Water consumption, $U_{w}$. The annual water intake of an adult as reported in ICRP 23 (1974) is $45-730 \mathrm{ml} \mathrm{d}^{-1}$, or $16-2701 \mathrm{y}^{-1}$. The USNRC suggests that a maximum value for an adult individual of $21 \mathrm{~d}^{-1}\left(7301 \mathrm{y}^{-1}\right)$ should be used to determine radiation dose from contaminated drinking water (USNRC, 1977). Recent water consumption data (Roseberry and Burmaster, 1992) indicate that the average adult drinking water consumption rate is described by a lognormal distribution with a geometric standard deviation of 1.6.

Aquatic food consumption, $U_{f}$. The mean daily intake of fish and seafood for an adult in the United States is $22 \mathrm{~g}$, or $8 \mathrm{~kg} \mathrm{y}^{-1}$ (ICRP, 1974). The USNRC reports a combined fish and invertebrate consumption rate of $7.9 \mathrm{y}^{-1}$ (USNRC, 1977). The Department of Agriculture states that the average annual consumption of fish and shellfish in the southern United States is $9.2 \mathrm{~kg}$ (Lutz et al., 1982).

Shellfish consumption comprises approximately $16 \%$ of the combined fish and shellfish consumption (USDA, 1983). Therefore, of the $9.2 \mathrm{~kg}$ of fish and shellfish consumed by individuals in the South over the course of the year, it was assumed that $84 \%$ (or $7.7 \mathrm{~kg} \mathrm{y}^{-1}$ ) represents the annual fish consumption. Individual consumption of shellfish is not considered to be a viable exposure pathway since the Savannah River is closed to shellfishing.

A lognormal distribution with a geometric standard deviation of 2.1 was determined to be representative of individual food consumption based on national consumption data (Pao et al., 1992). The variability in the data reported by Pao et al.(1992) for the nation was assumed to be indicative of the variation in fish and shellfish consumption in the southern United States.

Transport times, $t$. The transport time represents the elapsed time from release to exposure allowing for radioactive decay of nuclides in the Savannah River. For relatively long-lived radionuclides, such as those which are the focus of this study, transport times are unimportant since they are relatively short (on the order of days). Accordingly, each occurrence of the radioactive decay exponential is set equal to unity.

Water-to-sediment transfer coefficient, $K_{c}$. For the models in the Regulatory Guide 1.109 (USNRC, 1977), the water-to-sediment transfer constant has a fixed value 
of $0.072 \mathrm{~kg}^{-1} \mathrm{~h}^{-1}$. The value of $K_{c}$ was determined from the NRC's definition of the effective surface concentration (USNRC, 1977) as given by:

$$
S=1001 \mathrm{~m}^{-2} \mathrm{~d}^{-1}=K_{c}\left(40 \mathrm{~kg} \mathrm{~m}^{-2}\right)\left(24 \mathrm{~h} \mathrm{~d}^{-1}\right)(0.693)^{-1} .
$$

The value of $S$, when multiplied by the concentration of radionuclide $i$ in the water, the radiological half-life, the shoreline width factor, and additional buildup term gives an order of magnitude estimate of the effective surface area concentration (Soldat et al., 1974). Variation in the value of $K_{c}$ will obviously vary the resulting sediment concentration. Due to a lack of site-specific data for values of $K_{c}$ and its tremendous variability, a uniform distribution was assigned to this parameter with the value of $K_{c}$ varying one order of magnitude in each direction (i.e., $0.72-0.0072$ $\left.1 \mathrm{~kg}^{-1} \mathrm{~h}^{-1}\right)$.

Tritium absorption rate, $A_{s}$. The absorption of tritium through the skin for both air and water immersion have been investigated (Pinson and Langham, 1957); Osborne, 1966). Data gathered by Pinson and Langham concerning the skin's rate of tritium absorption in the liquid and vapor phase were used to determine the rate of water absorption through the skin. Analysis of their data indicates that water in the vapor phase is absorbed at a rate of $14 \mathrm{ml} \mathrm{h}^{-1}$ in an atmosphere of $100 \%$ relative humidity at a temperature of $24^{\circ} \mathrm{C}$, whereas the absorption rate increases to $35 \mathrm{ml} \mathrm{h}^{-1}$ during complete immersion in water at the same temperature (Hamby, 1992b).

Absorption of water through the skin is a physiological function which will vary from person-to-person depending on many factors such as the state of hydration, the surface area of the body, the absolute humidity, and the temperature. For the purposes of this study, the rate of tritium absorption through the skin is assumed to follow a normal distribution with a mean of $35 \mathrm{ml} \mathrm{h}^{-1}$. The variation was estimated by examining the water absorption data recorded by Pinson and Langham (1957). Variation of water absorption among subjects leads to an estimated standard deviation of about $25 \%$ of the mean. The tritium parameter, therefore, is described by a normal distribution with a mean and standard deviation of $35 \pm 8 \mathrm{ml} \mathrm{h}^{-1}$.

Shoreline width factor, $w$. The shoreline width factors used by the Nuclear Regulatory Commission (USNRC, 1977) were derived from experimental data (NIDE, 1971) and represent the fraction of the dose received from an infinite plane source estimated for several shoreline situations. Values of the shoreline width factor appropriate for various exposure regimes are given in Table IV.

The Savannah River environment/topography encompasses virtually all exposure situations, therefore a triangular distribution was chosen to describe the shoreline width factor with a minimum value of 0.1 , a maximum value of 1.0 , and a mode of 0.2 . 
TABLE IV

Shoreline exposure situations and associated width factors (NRC, 1977)

\begin{tabular}{ll}
\hline Exposure situation & Shoreline width factor \\
\hline Discharge canal bank & 0.1 \\
River shoreline & 0.2 \\
Lake shore & 0.3 \\
Ocean shore & 0.5 \\
Tidal basin & 1.0 \\
\hline
\end{tabular}

Bioaccumulation in freshwater organisms, $b_{k}$. The bioaccumulation factor, or bioconcentration ratio, for aquatic organisms is defined as the steady-state ratio of the radionuclide concentration in the organism to the concentration in water. The bioconcentration ratio is a complex variable which is dependent on many factors. As a result, individual measurements of bioconcentration ratios show great variability up to two orders of magnitude (Whicker and Shultz, 1982). Distributions assigned to the bioconcentration ratios for ${ }^{3} \mathrm{H},{ }^{90} \mathrm{Sr},{ }^{137} \mathrm{Cs}$ and ${ }^{239} \mathrm{Pu}$ are based on the range of values exhibited by these radionuclides from several sources in the literature (Thompson et al., 1972; Vanderploeg et al., 1975; Polikarpov, 1966).

Multiple sources estimate that the biocencentration ratio for ${ }^{3} \mathrm{H}$ is between 0.9 and $1.01 \mathrm{~kg}^{-1}$. A triangular distribution, therefore, was assigned to ${ }^{3} \mathrm{H}$ with a minimum value of 0.9 and a maximum and mode of $1.01 \mathrm{~kg}^{-1}$. Insufficient location-specific data resulted in the assignment of uniform distributions to the freshwater biocentration ratios for ${ }^{90} \mathrm{Sr},{ }^{137} \mathrm{Cs}$, and ${ }^{239} \mathrm{Pu}$. The ranges encompassed by these distributions are evident from Table III.

Release amounts, $A_{k}$. With detection techniques employed at the Savannah River Site, ${ }^{3} \mathrm{H}$ and ${ }^{137} \mathrm{Cs}$ release determinations, generally, are accurate to within 10 to $30 \%$. In the case of ${ }^{90} \mathrm{Sr}$ and ${ }^{239} \mathrm{Pu}$, the proximity of the measured release amounts to the lower limit of detection results in uncertainties up to $100 \%$. $^{*}$ These uncertainties have been incorporated into the distribution assignments for radionuclide release amounts. Triangular distributions were assigned to each release value, with the mode equal to the 1992 measured release (WSRC, 1993). For ${ }^{3} \mathrm{H}$ and ${ }^{137} \mathrm{Cs}$, ranges of possible values were varied by a factor of 1.3 above and below the mode while release amounts for ${ }^{90} \mathrm{Sr}$ and ${ }^{239} \mathrm{Pu}$ were allowed to vary by a factor of 2 .

Dose factors, $f$. Dose conversion factors (DCFs) utilized in the models are held constant and are based on the methodology of the International Commission on

* Personal communication, C. Hetrick, Westinghouse Savannah River Company, Environmental Monitoring Section, 18 May 1993. 
TABLE V

Internal and external dose factors used for the estimation of total effective dose equivalent

\begin{tabular}{llllll}
\hline & \multicolumn{2}{l}{ Internal dose factors } & & \multicolumn{2}{l}{ External dose factors } \\
\cline { 2 - 3 } \cline { 5 - 6 } Radionuclide & $\begin{array}{l}\text { Ingestion } \\
(\mu \mathrm{Sv} / \mathrm{Bq})\end{array}$ & $\begin{array}{l}\text { Inhalation } \\
(\mu \mathrm{Sv} / \mathrm{Bq})\end{array}$ & & $\begin{array}{l}\text { Ground shine } \\
\left(\mu \mathrm{Sv} \mathrm{m}{ }^{2} / \mathrm{yr} \mathrm{Bq}\right)\end{array}$ & $\begin{array}{l}\text { Water submersion } \\
\left(\mu \mathrm{Sv} \mathrm{m} \mathrm{m}^{3} / \mathrm{yr} \mathrm{Bq}\right)\end{array}$ \\
\hline $\mathrm{H}-3$ & $1.7 \mathrm{e}-4$ & $2.6 \mathrm{e}-4$ & & 0 & 0 \\
$\mathrm{Si}-90$ & 0.35 & 3.5 & & 0 & 0 \\
$\mathrm{Cs}-137$ & 0.14 & 0.086 & & 0.017 & 0.0018 \\
$\mathrm{Pu}-239$ & 11.6 & 1380 & & $1.0 \mathrm{e}-5$ & $2.6 \mathrm{e}-7$ \\
\hline
\end{tabular}

Radiological Protection (ICRP) Publications 26 (1977) and 30 (1979). The DCFs for ingestion represent the 50-year cumulative dose equivalent per unit intake of a radionuclide following a one-year exposure (USDOE, 1988b). External DCFs represent the dose equivalent rate received from exposure to a contaminated surface or immersion in water (USDOE, 1988a). Values for the DCFs utilized here are given in Table V.

\subsection{INPUT PARAMETER SAMPLING TECHNIQUE}

Uncertainty determination. The quantification of uncertainty was accomplished using a multivariate approach in conjunction with a Latin hypercube method for sampling from the parameter distributions (IAEA, 1989). Using the Latin hypercube method, input parameters were varied over their assigned range of values to obtain a representative distribution of radiation dose. The relative variability of the resulting dose distribution was utilized as the measure of uncertainty. Estimates of the uncertainty in total dose were obtained with 1000 Latin hypercube iterations while pathway and nuclide dependent uncertainties were determined using 300 iterations.

Sensitivity analysis. Determination of parameter sensitivity was accomplished using the coefficient of variability, defined as the ratio of a distribution's standard deviation to its mean. The coefficient is calculated from the dose distribution obtained by varying each input parameter separately. It provides a measure of the variation in the model output given that the input parameter is allowed to vary about its distribution while all other input values are held constant. The coefficient of variability is easily calculated and has been shown to be an excellent predictor of parameter sensitivity(Hamby, 1995). 
TABLE VI

Characteristics of dose distributions by pathway and nuclide

\begin{tabular}{lcllll}
\hline & \multicolumn{5}{c}{ Distribution percentiles } \\
& Range $^{\mathrm{a}}$ & 50 & 75 & 95 & Mean \\
\hline Total dose $(\mu \mathrm{Sv})$ & $0.32-2.8$ & 0.89 & 1.3 & 2.2 & 1.0 \\
Dose by pathway $(\mu \mathrm{Sv})$ & & & & & \\
$\quad$ Aquatic food consumption & $0.040-3.4$ & 0.43 & 0.73 & 1.6 & 0.56 \\
Water consumption & $0.93-1.6$ & 0.43 & 0.59 & 0.93 & 0.48 \\
Shoreline exposure & $0-0.1$ & 0.018 & 0.034 & 0.068 & 0.024 \\
Recreational activities & $0.00011-0.00057$ & 0.0003 & 0.0003 & 0.0005 & 0.0002 \\
Dose by radionuclide $(\mu \mathrm{Sv})$ & & & & & \\
H-3 & $0.11-1.2$ & 0.35 & 0.48 & 0.78 & 0.39 \\
Sr-90 & $0.025-0.94$ & 0.16 & 0.27 & 0.57 & 0.22 \\
Cs-137 & $0.023-2.7$ & 0.27 & 0.49 & .1 .1 & 0.38 \\
Pu-239 & $0.011-0.17$ & 0.044 & 0.061 & 0.093 & 0.048 \\
\hline
\end{tabular}

${ }^{\text {a }}$ At $99 \%$ confidence.

\section{Results}

The primary focus of this study was to quantify the uncertainty associated with estimates of radiation dose to members of the general public as a result of annual exposure to radioactivity released in liquid effluents from the Savannah River Site. Values were determined for the range of dose estimates, arbitrary percentiles (50th, 75th, and 95th), and the mean of the resulting dose distributions (see Table VI). In the calculated distributions, individual dose is plotted against the frequency of occurrence of each dose calculation, i.e., the relative probability of dose. The sensitivity of the pathway models to each of the parameters was also investigated.

For comparison, point-estimates of the radiation dose for each pathway also were calculated. These estimates are based on the average values of the normal and lognormal parameter distributions, mode values for triangular distributions, and median values in the case of uniform distributions.

Uncertainty in the estimate of total dose. Total dose uncertainty was determined for the assessment of individual dose from an aqueous release to the Savannah River. Uncertainty is measured by the variability present in the resulting dose distribution. The distribution for total individual dose (Figure 1) was determined to have a mean value of $1.0 \mu \mathrm{Sv}$ and a most probable value of $0.83 \mu \mathrm{Sv}$. The point-estimate value of total individual dose $(0.55 \mu \mathrm{Sv})$ falls within the $99 \%$ confidence range, 0.32 to $2.8 \mu \mathrm{Sv}$. 


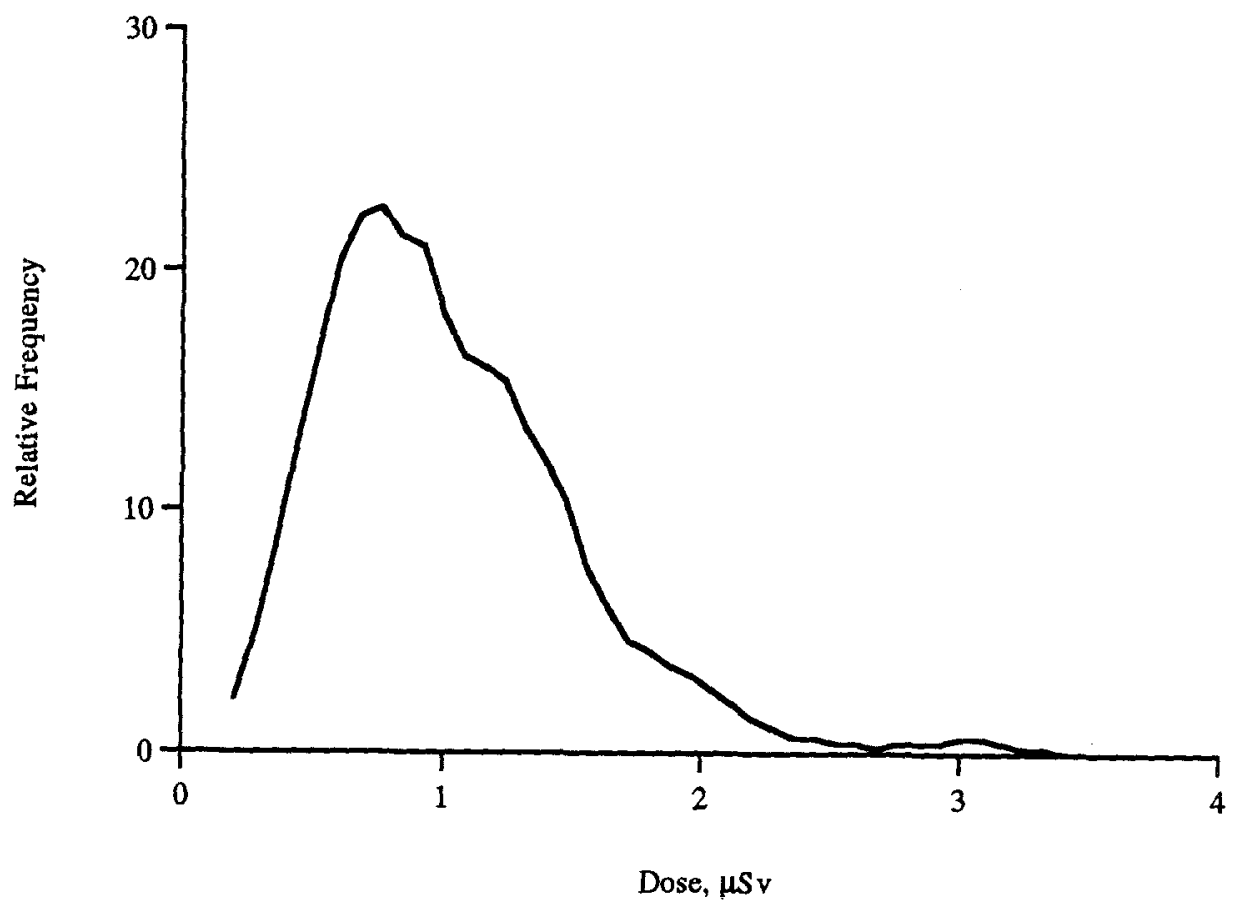

Fig. 1. Dose distribution for individuals exposed to radionuclides from annual aqueous releases to the Savannah River.

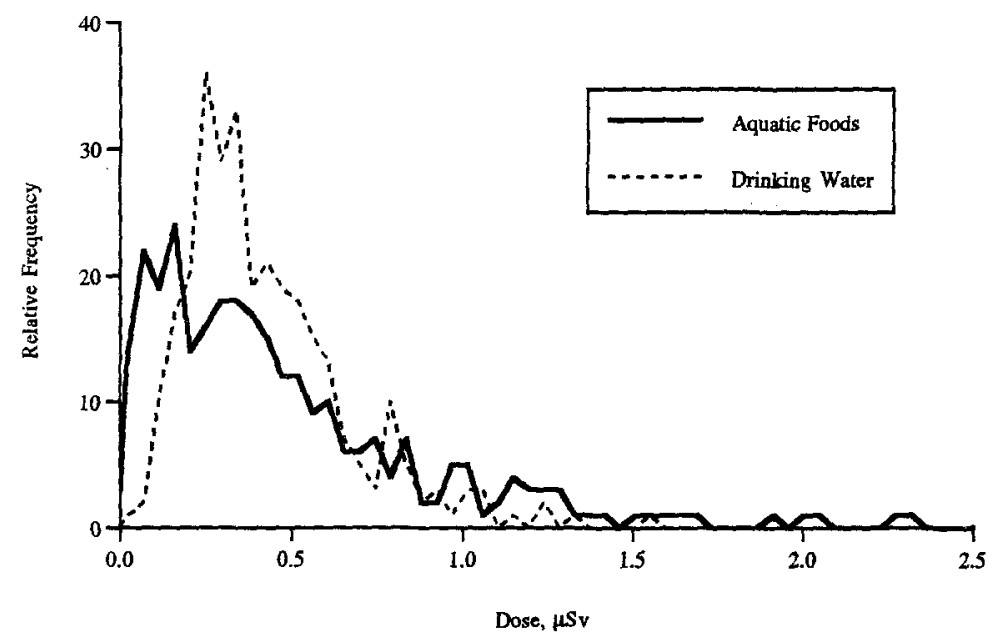

Fig. 2. Dose distributions for the aquatic foods consumption and water ingestion pathways. 


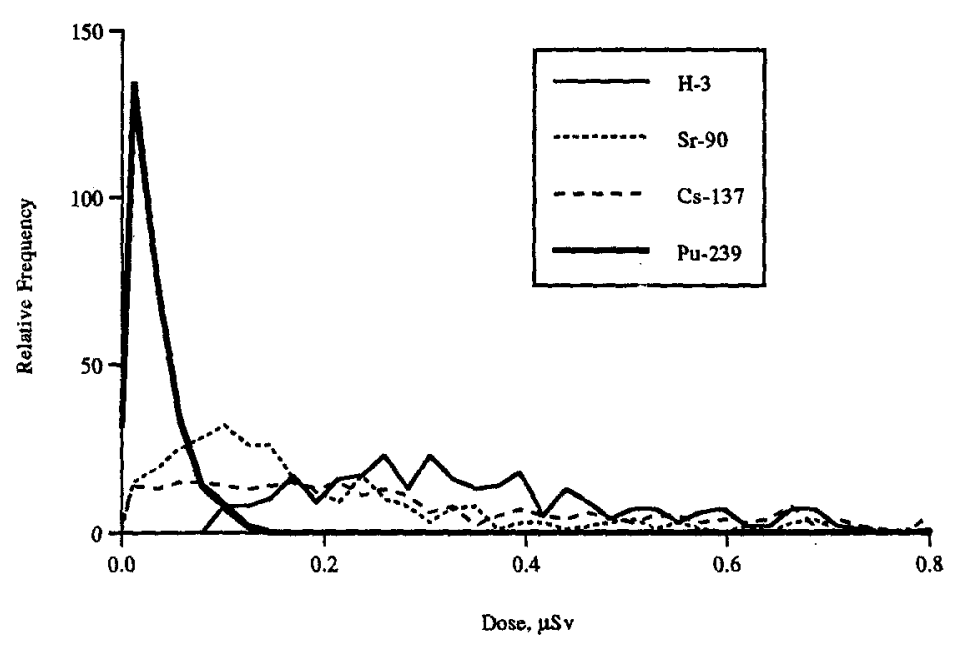

Fig. 3. Dose distributions for the four primary radionuclides contributing to total dose.

Pathway analysis. An investigation into the pathway contribution to the uncertainty in total dose was also conducted. A comparison of the contribution of dominant exposure pathways, aquatic food and water consumption, to total dose is given in Figure 2. Mean and mode values were determined to be $0.56 \mu \mathrm{Sv}$ and 0.23 $\mu \mathrm{Sv}$ respectively for aquatic food consumption dose. Water consumption dose was characterized by a mean of $0.48 \mu \mathrm{Sv}$ and a mode of $0.38 \mu \mathrm{Sv}$. The shoreline dose (not shown) exhibits a mean and mode of $0.024 \mu \mathrm{Sv}$ and $0.010 \mu \mathrm{Sv}$, respectively. The recreational dose contribution is even less significant.

Nuclide contributions to dose. The contribution to dose uncertainty by radionuclide was investigated and it was found that the ${ }^{3} \mathrm{H}$ and ${ }^{137} \mathrm{Cs}$ contributions to the radiation dose are approximately two times greater than the ${ }^{90} \mathrm{Sr}$ contribution, and a factor of about ten times greater than the ${ }^{239} \mathrm{Pu}$ contribution. Figure 3 contrasts the contributions by nuclide showing that total dose is dominated by ${ }^{3} \mathrm{H}$ and ${ }^{137} \mathrm{Cs}$. Tritium and ${ }^{137} \mathrm{Cs}$ contributed an average of 0.39 and $0.38 \mu \mathrm{Sv}$, respectively, to the mean.

Parameter sensitivity. The sensitivity of the pathway models to variations in the values of the 45 parameters was investigated. A list of the results of the sensitivity analysis is provided in Table VII. The list is arranged in descending order of parameter sensitivity for each pathway using the coefficient of variability as the sensitivity measure. The calculation of total dose was found to be most sensitive to the parameter of individual water and fish consumption and the biconcentration ratios of ${ }^{137} \mathrm{Cs}$ and ${ }^{90} \mathrm{Sr}$ for freshwater organisms. 
TABLE VII

Parameter sensitivity ranking by dose model

\begin{tabular}{lll}
\hline Pathway & Parameter & $\begin{array}{l}\text { Coefficient of } \\
\text { variability }\end{array}$ \\
\hline Total dose & Water consumption rate & 0.383 \\
& Fish consumption rate & 0.306 \\
& Bioconcentration, Cs-137 & 0.223 \\
& Bioconcentration, Sr-90 & 0.101 \\
Aquatic foods ingestion & Fish consumption rate & 0.971 \\
& Bioconcentration, Cs-137 & 0.520 \\
& Bioconcentration, Sr-90 & 0.281 \\
Water ingestion & Water consumption rate & 0.503 \\
& Release amount, H-3 & 0.089 \\
Shoreline exposure & Water-to-sediment transfer constant & 0.567 \\
& Shoreline width factor & 0.465 \\
& Shoreline usage & 0.232 \\
Recreational exposure & Swimming usage & 0.232 \\
& Tritium absorption rate & 0.227 \\
\hline
\end{tabular}

\section{Conclusions}

The models used here to estimate radiation dose to an individual exposed to an annual aqueous release of radioactive materials provide a range of possible dose estimates that span approximately one order of magnitude. The dose distributions representing the total dose to an individual span a range (at 99\% confidence) of 0.32 to $2.8 \mu \mathrm{Sv}$. Distribution biases were investigated by assigning uniform distributions to each parameter and reevaluating the dose distribution. As expected, the assignment of uniform distributions to all parameters increases the uncertainty in the dose estimate in this case to more than two orders of magnitude. It is concluded, therefore, that assessment variability (uncertainty) may be reduced with a greater knowledge of the important parameters in the assessment.

Analysis of the exposure pathways reveals that aquatic food and water consumption account for more than $95 \%$ of the total dose to an individual. Recreational doses from swimming and boating and shoreline activities are insignificant when compared to the dose received via the ingestion pathways.

Radiation dose from ${ }^{3} \mathrm{H}$ and ${ }^{137} \mathrm{Cs}$ dominates the total dose from routine aqueous releases at the SRS. Tritium and ${ }^{137} \mathrm{Cs}$ account for over $75 \%$ of the total dose 
to an individual. The ${ }^{137} \mathrm{Cs}$ dose is attributable to the ingestion of contaminated aquatic food. Freshwater organisms concentrate cesium in their tissues to a greater extent than that observed for tritium, strontium, and plutonium. Therefore, ingestion of aquatic food contaminated with cesium will result in a greater dose commitment relative to those received from ingesting food contaminated with the other nuclides.

The coefficient of variability is used here to provide a measure of the importance of a given model parametc and an indication of the sensitivity of the model to that parameter. Individual total dose was shown to be most sensitive to water and fish consumption rates. Bioconcentration factors for ${ }^{137} \mathrm{Cs}$ and ${ }^{90} \mathrm{Sr}$ were determined to be the third and fourth most sensitive parameters in the model for total dose. All four of these parameters are included in the aquatic food and water ingestion pathways which dominate the individual dose.

\section{Acknowledgments}

This research was performed under appointment to the Nuclear Engineering/Health Physics Fellowship program administered by Oak Ridge Institute for Science and Education for the U.S. Department of Energy. The information contained in this document was developed during the course of work under Contract DE-AC0989SR18035 with the U.S. Department Energy.

\section{References}

Georgia Department of Natural resources: 1990, 'Outdoor Recreation Assessment and Policy Plan 1989, in the Georgia Recreation Planning Processes', Atlanta, GA.

Hamby, D. M.: 1992a, 'Site-specific Parameter Values for the Nuclear Regulatory Commission's Food Pathway Dose Model', Health Physics 62, 136-143.

Hamby, D. M.: 1992b, 'A Methodology for Estimating the Radiological Consequence of an Acute Aqueous Release', Health Physics 62, 567-570.

Hamby, D. M.: 1995, 'A Comparison of Sensitivity Analysis Techniques', Health Physics 68, 195204.

International Atomic Energy Agency: 1989, 'Evaluating the Reliability of Predictions Made Using Environmental Transfer Models', Report No. 100, Vienna, Austria.

International Commission on Radiological Protection: 1974, 'Report of the Task Group on Reference Man', Report No. 23, Pergamon Press, new York.

International Commission on Radiological Protection: 1977, 'Recommendations of the International Commission on Radiological Protection', Report No. 26, Pergamon Press. New York.

International Commission on Radiological Protection, 'Limits for Intakes of Radionuclides by Workers, Part 1', Report No. 30, Pergamon Press, new York.

Lutz, S. M., Smallwood, D. M., Blaylock, J. R. and Hama, M. Y.: 1982, Changes in Food Consumption and Expenditures in American Households During the 1980s', Report No. 44, United States Department of Agriculture, Washington, D.C.

Northern Ireland Department of Employment,: 1971, Handbook of Radiological Protection, Part I: Data, Ministry of health and Social Services, Her Majesty's Stationery Office. London, Engeland: Report No. SNB 11-360079-8. 
Vanderploeg, H. A., Parzyck, D. C., Wilcox, W. H., Kercher, J. R. and Kaye, S. V.: 1975, 'Bioaccumulation Factors for Radionuclides in Freshwater Biota', Report No. ORNL-5002. Oak Ridge National Laboratory. Oak Ridge, TN.

Osborne, R. V.: 1966, 'Absorption of Tritiated Water Vapor by People', Health Physics 12, 15271537.

Pao, E. M., Fleming, K. H., Guenther, P. M. and Mickle, S. J.: 1992, 'Foods Commonly Eaten by Individuals: Amount Per Day and Per Eating Occasion', Report No. 849, United States Department of Agriculture. Washington, D.C.

Pinson, E. A. and Langham, W. H.: 1997, 'Physiology and Toxicology of tritium in Man', Journal of Applied Physiology 10, 108-126.

Polikarpov, G. G.: 1966, Radioecology of Aquatic Organisms, North-Holland, Amsterdam.

Roseberry, A. M. and Burmaster, D. E.: 1992, 'Longnormal Distributions for Water Intake by Childeren and Adults' Risk Analysis 12, 99-104.

Simpson, D. B. and McGill, B. L.: 1977, LADTAP II: A Program for Calculating Radiation Exposure to Man From Routine Release of Nuclear Reactor Liquid Effluents', Report No. NUREG/CR1276, Engineering Physics Division, Oak Ridge, TN.

Soldat, J. K., Robinson, N. M. and Baker, D. A.: 1974, 'Models and Computer Codes for Evaluating Environmental Radiation Doses, Report No. BNWL-1754, Pacific Northwest Laboratories. Richland, WA.

Thompson, S. E., Burton, C. A., Quinn, D. J. and Ng, Y. C.: 1972, 'Concentration Factors of Chemical Elements in Edible Aquatic Organisms', Report No. UCRL-50564, Rev. 1, Lawrence Livermore Laboratory, Livermore, CA.

Tsoulfanidis, N.: 1983, Measurement and Detection of Radiation, Hemisphere Publishing Corporation, new York.

United States department of Agriculture: 1993, Food Consumption: Households in the South, Seasons and year 1977-1978. Report No. H-9, Washington, DC.

United States Department of Energy: 1988a, 'External Dose Rate Conversion Factors for the Calculation of Dose to the Public', report No. DOE/EH-0070, Washington, DC.

United States Department of Energy: 1988b, Internal Dose Conversion Factors for the Calculation of Dose to the Public, Report No. DOE/EH-O07I, Washington, DC.

United States Geological Survey: 1993, 'Water Resources Data-Georgia Water Year 1992, Report No. GA-92-1, Washington, DC.

United States Nuclear Regulatory Commission, 'Calculation of Annual Doses to Man From Routine Releases of Reactor Effluents for the Purpose of Evaluating Compliance With 10 CFR Part 50, Appenfix I, Regulatory Guide 1, 109, Office of Standards development, Washington, DC.

Westinghouse Savannah River Company: 1989, Savannah River Site Environmental Report, Cummings, C. L. Martin, D. K. and Martin, J. L. (eds), Report No. WSRC-IM-90-60, Aiken, SC.

Westinghouse Savannah River Company: 1990, Savannah River Site Environmental Report, Cummings, C. L. Martin, D. K. and Martin, J. L. (eds), Report No. WSRC-IM-91-28, Aiken, SC.

Westinghouse Savannah River Company: 1991, Savannah River Site Environmental Report, Arnett, M. W. Karapatakis, L. K. Mamatey, A. R. and Todd, J. L. (eds), Report No. WSRC-TR-92-186, Aiken, SC.

Westinghouse Savannah River Company: 1992, Savannah River Site Environmental Report, Arnett, M. W. Karapatakis, L. K. and Mamatey, A. R. (eds), No. WSRC-TR-93-075, Aiken, SC.

Whicker, F. W., Schultz, V.: 1982, Radioecology Energy and the Environment, Vol. 2, CRC Press, Boca Raton, FL. 